\title{
A study protocol to determine the association between lifetime lead exposure and violent criminal behaviour in young males in conflict with the law
}

\author{
Thokozani P. Mbonane ${ }^{1 *}$ (D), Angela Mathee ${ }^{1,2,3}$, André Swart $^{1}$ and Nisha Naicker ${ }^{1,3,4}$
}

\begin{abstract}
Background: Low-level lead exposure has harmful and persistent effects on behaviour. Recent studies have linked environmental lead exposure and the development of aggressive, violent and criminal behaviour. This protocol is designed to study an association between lifetime (bone) lead levels and violent criminal behaviour among young males in conflict with the law in Gauteng youth development centres.

Methods: This paper describes a study to determine a link between lifetime lead exposure and violent criminal behaviour. Lifetime lead exposure will be measured using bone lead measurement, while blood lead levels will be observed for current exposure. Thereafter, criminal records of participants will be reviewed whereas violent behaviour and risk factors will be observed using a questionnaire. The study focused on young males in conflict with the law in three centres within Gauteng Provence, South Africa. After stratifying the centres, we randomly selected participants. The researcher shall adhere to ethical requirements throughout the study. Data will be analysed for descriptive and inferential analysis using Statistical Package for Social Science (SPSS).

Discussion: The study will provide a strong foundation for an improved understanding of the relationship between environmental contamination from lead exposure and aggression/violent criminal behaviour. Beyond the health sector, the study findings may be able to inform new approaches to crime prevention through environmental action with an emphasis on the role of non-health sectors.
\end{abstract}

Keywords: Bone, Blood, Lifetime, Lead exposure, Violent, Criminal, Behaviour, X-ray fluorescence, Environmental health

\section{Background}

Environmental lead exposure at an early life is a growing important risk factor to societal ill-behaviour [1, 2]. A recent study estimates that about 400,000 deaths per annum are attributable to lifetime lead in develop countries [3]. Yet, African children still have blood lead levels above $5 \mu \mathrm{g} / \mathrm{dL}$ [4]. There is growing evidence that links long-term environmental lea d exposure with neurological effects, violent and criminal behaviour [5-9].

Elevated blood lead levels may disturb the cells' biological metabolism through replacing useful ions in the

\footnotetext{
* Correspondence: tpmbonane@uj.ac.za

${ }^{1}$ Department of Environmental Health, Faculty of Health Sciences, University of Johannesburg, Johannesburg, South Africa

Full list of author information is available at the end of the article
}

body such as calcium, magnesium, iron and sodium. It also impairs or disrupts other biological processes in the human body $[10,11]$. According to Flora et al. once calcium has been substitute by lead, the protein kinase $C$ that regulates neural excitation and memory storage can be weakened [12]. This may lead to brain disorder resulting in reduced intelligent quotient, behavioural changes such as a shortened attention span, learning problems and increased antisocial behaviour such as violence and criminal acts [6, 13-15]. Ecological and epidemiological studies in developed countries have linked lead exposure to antisocial and criminal activities [16-22]. A retrospective cohort study conducted in the USA found that children with higher blood lead at birth were at risk of being arrested for a violent crime [23]. Similar findings were supported 
by studies conducted in other developed countries [7]. However, a study in New Zealand found that there is no causation relationship between higher blood levels and criminal activities [24].

South African children are still exposed to lead found in their living, playing and parents' working environments $[25,26]$. Little information is available in South Africa regarding the health effects of lead exposure [27], especially in adolescents, young adults in conflict with the law and specific high-risk groups. A recent study by Nkomo and colleagues found that males in early teens with elevated blood lead levels were at risk at perpetration violence behaviour in their late adolescence stage [5]. South African children still have blood lead levels above the Centers for Disease and Control and Prevention (CDC)'s recommended reference level of $5 \mu \mathrm{g} / \mathrm{dL}$ [28-31]. In addition South Africa, there is a high number of violent or aggressive crime such as murder, hijacking with weapons committed on a regular basis. Hence, it is important to understand the role of environmental lead exposure to criminal behaviour in developing countries (South Africa included). Therefore, this study aims to bridge the gap in the evidence of this risk in South Africa.

Based on evidence emerging from well-resourced countries [32], the current study hypothesizes that incarcerated young males in South Africa who have been charged or adjudicated for violent criminal acts have high bone and blood lead levels. The first objective of the study we determining and comparing bone and blood lead measurements in young males in conflict with the law in three youth development centres in Gauteng; secondly, determining and describing violent criminal behaviour and health status in the study population through the administration of a questionnaire that includes a behavioural assessment and lastly examine the association between lifetime (bone) and current (blood) lead levels and violent criminal behaviour among young males in conflict with the law in Gauteng youth development centres.

\section{Methods}

\section{Study design and population}

A cross-sectional analytical study was designed to determine the association between bone lead levels and violent criminal behaviour among South African young males in conflict with the law.

\section{Population and sampling}

The study population consists of young males aged 14-21 (age group accommodated in the facilities) who have committed and been convicted of a crime (ranging from serious violence to less serious crimes). These young males are accommodated at three child and youth development centres (namely Centre A, B \& C for the purpose for this study) in the Gauteng Province. Centre A houses a maximum of 50 young males convicted of serious crimes, Centre B provides beds for 100 young males that have committed less serious crimes, and Centre $\mathrm{C}$ accommodates 100 sentenced young males that have committed both serious and less serious crimes but have agreed to a diversion programme (rehabilitation services). We adopted a stratified random sampling technique to group the centres (centres were grouped according to the type of crime committed) and select participants. Each centre formed a stratum; thereafter participants are randomly sampled to avoid selection bias.

\section{Recruitment}

Firstly, the researchers requested and received permission from the Gauteng Department of Social Development to access the centres. Secondly, we approach the parents or legal guardians of a male under the age of 17 for consent to approach their children to partake in the study. Lastly, after receiving parental consent, we approach all the young males in the centres and sort assent and consent.

\section{Sample size determination}

The adequate sample size was calculated on the estimated population of 250 and prevalence of lead exposure and violent behaviour of 30\% (CI: 95\%), based on a study conducted amongst adolescents to determine the association between childhood lead exposure and violent behaviour [5]. We used the following equations to calculate for adequate sample size; where: $\mathrm{n}=$ minimum sample size; $\mathrm{Z}=$ standard normal deviate at $\alpha$ probability (1.96); $\mathrm{P}=$ Prevalence of BLLs and violent behaviour in South African male adolescents $(30 \%)$; $\mathrm{ME}=$ margin of error (0.05) and CI = confidence level (95\%).

\section{Data collection}

Different methods and tools were designed and adopted for data collection. Data will be collected in four phases; record review, questionnaire, blood sample, anthropometric measurements and bone measurement. The research assistants comprise a phlebotomist/nurse for blood sampling, as well as taking and calculating the calculate body mass index (BMI), while an XRF certified technologist (for taking bone lead measurements). In the first phase, the records of young males in the centres were reviewed in order to obtain their names for the allocation of numbers and the type of crime committed.

\section{In vivo bone lead measurement (tool 1)}

Tibial bone lead concentration levels are estimated using non-invasive in vivo $\mathrm{K}$-shell $\mathrm{X}$-ray fluorescence (KXRF). The KXRF technique is a biomarker used to determine cumulative lead exposure levels [33-37]. Participants in the study will be required to sit while the measurement 
system is fitted. The tibia of the study participant will be exposed to X-ray fluorescence for $30 \mathrm{~min}$. Participants' exposure to radiation due to X-rays is approximately $2.1 \mu \mathrm{Sv}$, which is less than the radiation experienced during chest X-rays [38]. Participants are expected to remain seated and still for this period. The participants do not experience any pain as the process is the same as for a normal X-ray. Once the readings (Resultant spectra) are captured, these will be sent to an expert from Mount Sinai University for analyses.

\section{Blood sample (tool 2)}

Venous blood samples $(50-100 \mu \mathrm{l})$ are collected from participants using a sterile (free of trace metals) test tube (BD Vacutainer system) containing the anticoagulant ethylene diamine tetra acetic acid (EDTA) by registered nurses from the SAMRC. All samples are analysed using Inductively Coupled Plasma Mass Spectrometry (ICPMS) for BLLs. A drop of the blood will be collected from the site where venous blood will be withdrawn, before applying pressure and plaster to assess for anaemia, to determine haemaglobin levels (since blood lead concentrations are affected by haemaglobin concentration).

\section{Questionnaire (tool 3)}

Information of the participants' parents' occupational history, socio-demographic, environmental issues, biological factors, and behavioural issues is ideally collected using a questionnaire. The questionnaire is translated by a competent person to isiZulu and seSotho for those who may not understand English.

\section{Data storage}

We created a profile on the REDCap software application, an online (secure web-based) application for data storage and management. Thereafter, the tools are preprogrammed on the REDCap software application to capture the responses and readings. After capturing the data on the application and all the responses have been completed, the data will be kept in the application and a password will be created by the principal investigator.

\section{Quality control}

The in vivo signal from a subject measured for each bone lead X-ray are analysed and compared to the established calibration line to obtain one or more estimates of the subject's bone-lead level. We sought assistance from an expert in the field for guidance during data collection and analysis. Furthermore, a qualified agent calibrates the instrument prior to commencing with the study. Blood samples will be taken by a professional nurse or doctor, currently registered with the Health Professions Council of South Africa (HPCSA) or/and South African Nursing Council (SANC). Thereafter, refrigerated prior to being transported to an accredited laboratory, which conforms to international and national quality control standards [39]. The questionnaire was constructed and finalized with the assistance of the study supervisors and a biostatistician. We piloted the questionnaire in advance to identify concerns and institute refinements.

\section{Data management and analysis}

Data from the questionnaire, bone measurements and BLLs readings are entered and captured on REDCap for storage, data cleaning, and identifying missing data. Thereafter, data transferred to SPSS statistical analysis programme for data analysis. A score is developed from the two behaviour checklists behavioural assessment section, type of crime committed will be classified according to serious or less crime and based on the established criteria will be categorised as indicating violent and criminal. Based on the behaviour checklists and criminal record established criteria will be categorised as having violent criminal behaviour or not (binary variable). Bone and blood lead distributions and criminal record information will be analysed for normality and presented using descriptive statistics (range, median, mean, standard deviation, 95\% confidence intervals); while nonnormally distributed variables will be log-transformed and analysed using parametric tests (Analysis of variance - ANOVA). The relationships between the dependent variables (bone and lead levels) and independent variables (socio-demographic, environmental and showing violent criminal behaviour) will be determined using multiple bivariate logistic regression techniques (will be presented in odds ratios). We will use a stepwise method, where a liberal criterion ( $p$-value) of 0.2 will be used to select variables. Then a backward or maximum likelihood ratio test for variables inclusion criteria will be implemented to select variables significant at the $95 \%$ confidence interval for the multivariable regression to estimate the likelihood of having an outcome of interest (violent criminal behaviour). Furthermore, ANOVA and multivariate linear regression modelling will be used to compare mean blood and bone lead levels among the study participants of the three centres. Continuous variable (bone lead and blood lead) will be categorised, for example, blood lead $(0 \leq 5 \mu \mathrm{d} / \mathrm{dL}$ and $1>5 \mu \mathrm{d} / \mathrm{dL})$ and bone lead $(0 \leq 25 \mathrm{ppm}$ and $1>25 \mathrm{ppm})$. Pearson's chisquare $(x 2)$, Fisher's exact, proportionality and two sample student t-test tests and ANOVA will be applied to determine the association among blood, bone lead levels, violent criminal behaviour and confounding variables.

\section{Outcomes}

The primary outcome of this study is to describe the association between lifetime environmental lead exposure and violent criminal behaviour. Furthermore, to describe 
the difference in bone and blood lead levels in young males that are in the juvenile centre. After controlling for confounding factors such: age, parental educational levels, parents occupation, backyard business, socioeconomy status, smoking, residential proximity to industries and drinking water from lead water-taps.

\section{Dissemination}

We aim to disseminate the results from the study to the participants, policymakers in the health and criminal justice sector through presentations and official report. Furthermore, presents at relevant conferences and publish the findings in peer-reviewed publications.

\section{Study progress}

The study has received ethical approval to commence with the project. All the lists of young males from different centres have been received and parents of males under the age of 18 years have been approach for consent. The researchers are currently busy with data collection (study ongoing).

\section{Discussion}

Studies have shown that lead exposure remains high in developing countries, including South Africa [2, 30, 40]. Despite continued exposure to lead, especially in children of low socio-economic status, there is a dearth of information on the contribution of lead exposure to violent criminal behaviour in South Africa. This study is the first (according to our knowledge) study in South Africa to look at the association between violent criminal behaviour and lead in blood (acute exposure) and bone (a lifetime exposure) among young males in conflict with the law.

Regardless of the higher burden of lead exposure in South Africa and other countries, gaps still exist in the knowledge of lead exposure and its impact on adolescents and young adults. One of the strengths of this study is that it seeks to understand the lifetime lead exposure with violent criminal behaviour during late adolescence and young adulthood. Most of the studies have compared blood lead levels when they were children with an antisocial tendency at a later stage. These studies did not consider accumulative lead levels from longterm exposure, which exclude lifetime exposure lead index. This study will contribute to the knowledge gaps on the effect of lifetime lead exposure on antisocial behaviour in South Africa and internationally. In recent years few studies have been reported that associated blood lead levels with antisocial behaviour such as aggressive and violent behaviour in South Africa. In this study, we going to measure for both cumulative and recent exposure and compare these lead levels. This is believed to be more informative than looking at one type of exposure. Secondly, the study will use two different approaches to determine aggressive and criminal tendencies, which will ensure that the outcome of interest is verified and supported.

Neurobehavioral effects link to lead exposure are preventable and reversible. A prospective longitudinal study in Taiwan conducted amongst lead workers showed that the implementation of an intervention programme is essential to reduce blood lead levels has the potential to reverse neurobehavioural caused by lead exposure [41]. It is important to understand the role of lead exposure to violent and criminal tendencies, thus contributing to the fight against crime using environmental health intervention programmes.

The limitation of the study is that it seeks to identify an association between violent criminal behaviour that occurred before the participants were placed in the centres. Therefore, it would not be able to determine causation of the phenomena. Furthermore, the study will compare children in conflict with the law only and based on the crime committed using a cross-sectional study.

\section{Abbreviations \\ ANOVA: Analysis of variances; BLL: Blood lead levels; BMI: Body mass index; CDC: Centers for Disease Control and Prevention; EDTA: Ethylene diamine tetra acetic acid; HPCSA: Health Professional Council of South Africa; ICP- MS: Inductively coupled plasma mass spectrometry; KXRF: K-shell X-ray fluor- escence; ME: Margin of error; ppm: parts per million; REC: Research ethics committee; SAMRC: South African Medical Research Council; SANC: South African Nursing Council; SSPS: Statistical Package for Social science; USA: United Nations of America; XRF: X-ray fluorescence; $\mu \mathrm{g} / \mathrm{dL}$ : microgram per deciliter; $\mu \mathrm{Sv}$ : microsieverts}

\section{Acknowledgements}

N/A

\section{Authors' contributions}

Drafting of protocol, TPM; Drafting final manuscript, TPM, NN, AM and AS.; methodology, TPM, NN, AM and AS. All the authors read and approved the final version.

\section{Funding}

This project received a block grant scholarship for the lead author from National Research Council (NRF). NRF (or officials) from did not take part in the design of the study and collection, analysis, and interpretation of data and in writing the manuscript.

\section{Availability of data and materials}

Data sharing is not applicable to this article as no datasets were generated or analysed during the current study.

\section{Ethics approval and consent to participate}

We received an ethical clearance (REC-241112-035) from the University of Johannesburg, Faculty of Health Sciences' Research Ethics Committee and academic merits from the Higher Degree Committee. Furthermore, permission from the Gauteng Department of Social Development reference no 2/9/05 has been granted. The researchers requested parental or legal guardian consent (from parents of males under the age of 17) prior to the commencement of the study. Thereafter, the researchers invited participants to a private room/venue and address them in the absence of their parents and legal guardians to inform them about the aims and objectives of the study, their right of refusal to take part in or withdraw from the study at any time, without any punitive action or requirement to provide reasons, and their participation will not affect parole and correctional programming decisions. Furthermore, participants under the age of 17 gave assent and males over 18 years gave consent to participating in the study. Those who 
will turn 18 during the study will be required to give consent again. Where consent was given by the parent or legal guardian but not by the relevant participant and vice versa, the participants were not approach or included in the study. Participation in the study was anonymous (numbers will be allocated to the participants for identification). The researchers treat all information (including the database of the participants from the facilities) collected confidentially. Only the researcher and the supervisors have access to the secure information collected. The biostatistician was given a password to assess the data, which will expire once the analysis is completed. Data collected shall not be made available to anyone, and will be used for research purposes only.

\section{Consent for publication}

N/A

\section{Competing interests}

The authors declare that they have no competing interests.

\section{Author details}

${ }^{1}$ Department of Environmental Health, Faculty of Health Sciences, University of Johannesburg, Johannesburg, South Africa. ${ }^{2}$ Environment and Health Research Unit, South African Medical Research Council, Johannesburg, South Africa. ${ }^{3}$ School of Public Health, Faculty of Health Sciences, University of the Witwatersrand, Johannesburg, South Africa. ${ }^{4}$ The Epidemiology and Surveillance Section, National Institute for Occupational Health, National Health Laboratory Services, Johannesburg 2000, South Africa.

\section{Received: 20 April 2019 Accepted: 21 May 2019}

\section{Published online: 11 July 2019}

\section{References}

1. Olympio KPK, Oliveira PV, Naozuka J, Cardoso MRA, Marques AF, Günther WMR, et al. Surface dental enamel lead levels and antisocial behavior in Brazilian adolescents. Neurotoxicol Teratol. 2010;32(2):273-9. Available from. https://doi.org/10.1016/j.ntt.2009.12.003.

2. Naicker N, Richter L, Mathee A, Becker P, Norris SA. Environmental lead exposure and socio-behavioural adjustment in the early teens: the birth to twenty cohort. Sci Total Environ. 2012;414:120-125. Available from. https:// doi.org/10.1016/j.scitotenv.2011.11.013.3.

3. Lanphear BP, Rauch S, Auinger P, Allen RW, Hornung RW. Low-level lead exposure and mortality in US adults: a population-based cohort study. Lancet Public Health. 2018;3(4):e177-84. Available from. https://doi.org/10. 1016/S2468-2667(18)30025-2.

4. WHO. Lead exposure in African children: contemporary sources and concern. Johannesburg: WHO African region press; 2015. http://apps.who. int/iris/bitstream/10665/200168/1/9780869707876.pdf.

5. Nkomo P, Galpin J, Mathee A, Richter LM, Norris SA, Naicker N. The association between elevated blood lead levels and violent behavior during late adolescence: the south African birth to twenty plus cohort. Environ Int. 2017:109:136-45. Available from. https://doi.org/10.1016/j.envint.2017.09.004.

6. Nevin R. How Lead exposure relates to temporal changes in $I Q$, violent crime, and unwed pregnancy. Environ Res. 2000;83(1):1-22. https://doi.org/ 10.1006/enrs.1999.4045.

7. Nevin R. Understanding international crime trends: the legacy of preschool lead exposure. Environ Res. 2007;104(3):315-36.

8. Feigenbaum JJ, Muller C. Lead exposure and violent crime in the early twentieth century. Explor Econ Hist. 2016;62:51-86. Available from: https:// doi.org/10.1016/j.eeh.2016.03.002.

9. Nriagu J. Lead, Deliquency and violence. In: Encyclopedia of environmental health: Elsevier; 2011. p. 412-20. Available from: https://doi.org/10.1016/ B978-0-444-52272-6.00138-0.

10. Ayala A, Muñoz MF, Argüelles S. Lipid peroxidation: production, metabolism, and signaling mechanisms of malondialdehyde and 4-Hydroxy-2-Nonenal. Oxidative Med Cell Longev. 2014;2014:1-31. https://doi.org/10.1155/2014/ 360438.

11. Mason LH, Harp JP, Han DY. Pb neurotoxicity: neuropsychological effects of lead toxicity. Biomed Res Int. 2014;2014:840547. Available from: http://dx.doi. org/10.1155/2014/840547.

12. Flora G, Gupta D, Tiwari A. Toxicity of lead: a review with recent updates. Interdiscip Toxicol. 2012;5(2):47-58. https://doi.org/10.2478/ v10102-012-0009-2.
13. Needleman H. Low level Lead exposure: history and discovery. Ann Epidemiol. 2009;19(4):235-8. Available from. https://doi.org/10.1016/j. annepidem.2009.01.022.

14. Denno DW, Biology RDC. Violence: from birth to adulthood. Contemp Sociol. 2006;21(5):699.

15. Liu J, Li L, Wang Y, Yan C, Liu X. Impact of low blood Lead concentrations on IQ and school performance in Chinese children. Sun Q, editor. PLoS One. 2013;8(5):e65230. https://doi.org/10.1371/journal.pone.0065230.

16. Taylor MP, Forbes MK, Opeskin B, Parr N, Lanphear BP. The relationship between atmospheric lead emissions and aggressive crime: an ecological study. Environ Health. 2016;15(1):23. Available from. https:// doi.org/10.1186/s12940-016-0122-3.

17. Boutwell BB, Nelson EJ, Emo B, Vaughn MG, Schootman M, Rosenfeld R, et al. The intersection of aggregate-level lead exposure and crime. Environ Res. 2016:148(July):79-85.

18. Stretesky PB, Lynch MJ. The relationship between lead exposure and homicide. Arch Pediatr Adolesc Med. 2001;155(5):579-82.

19. Fergusson DM, Boden JM, Horwood LJ. Dentine lead levels in childhood and criminal behaviour in late adolescence and early adulthood. J Epidemiol Community Health. 2008;62(12):1045-50.

20. Sampson RJ, Winter AS. Poisoned development: assessing childhood lead exposure as a cause of crime in a birth cohort followed through adolescence. Criminology. 2018;56(2):269-301.

21. Dietrich KN, Douglas RM, Succop PA, Berger OG, Bornschein RL. Early exposure to lead and juvenile delinquency. Neurotoxicol Teratol. 2001. https://doi.org/10.1016/S0892-0362(01)00184-2.

22. Reyes JW. Lead exposure and behavior: effects on antisocial and risky behavior among children and adolescents. Econ Inq. 2015;53(3).

23. Wright JP, Dietrich KN, Ris MD, Hornung RW, Wessel SD, Lanphear BP, et al. Association of prenatal and childhood blood lead concentrations with criminal arrests in early adulthood. PLoS Med. 2008. https://doi.org/10.1016/ S0892-0362(01)00184-2.

24. Beckley AL, Caspi A, Broadbent J, Harrington H, Houts RM, Poulton R, et al Association of childhood blood lead levels with criminal offending. JAMA Pediatr. 2018;172(2):166-73.

25. Mathee A, Singh E, Mogotsi M, Timothy G, Maduka B, Olivier J, et al. Leadbased paint on playground equipment in public children's parks in Johannesburg, Tshwane and Ekurhuleni. S Afr Med J. 2009;99(11):819-21. Available from: http://www.scielo.org.za/scielo.php?script=sci_arttext\&pid= S0256-95742009001100025.

26. Mathee A, Naicker N, Kootbodien T, Mahuma T, Nkomo P, Naik I, et al. A cross-sectional analytical study of geophagia practices and blood metal concentrations in pregnant women in Johannesburg, South Africa. S Afr Med J. 2014;104(8):568-73. https://doi.org/10.7196/samj.7466.

27. Naicker N, Norris SA, Mathee A, Von SYE, Richter L. Prenatal and adolescent blood lead levels in South Africa : child, maternal and household risk factors in the birth to twenty cohort. Environ Res. 2010;110(4):355-62. Available from. https://doi.org/10.1016/j.envres.2010.02.006.

28. Von Schirnding Y, Bradshaw D, Fuggle R, Stokol M. Blood lead levels in south African inner-city children. Environ Health Perspect. 1991;94:125-30. https://doi.org/10.1289/ehp.94-1567937.

29. Mathee A, Röllin H, Von Schirnding Y, Levin J, Naik I. Reductions in blood lead levels among school children following the introduction of unleaded petrol in South Africa. Environ Res. 2006;100(3):319-322. https://doi.org/10. 1016/j.envres.2005.08.001.

30. Naicker N, Mathee A, Barnes B. A follow-up cross-sectional study of environmental lead exposure in early childhood in urban South Africa. S Afr Med J. 2013;103(12):935-8.

31. Nkomo P, Richter LM, Kagura J, Mathee A, Naicker N, Norris SA. Environmental lead exposure and pubertal trajectory classes in south African adolescent males and females. Sci Total Environ. 2018; 628-629:1437-45. Available from. https://doi.org/10.1016/j.scitotenv. 2018.02.150.

32. Needleman HL, McFarland C, Ness RB, Fienberg SE, Tobin MJ. Bone lead levels in adjudicated delinquents. A case control study. Neurotoxicol Teratol. 2002;24(6):711-7. https://doi.org/10.1016/S0892-0362(02)00269-6.

33. Hoppin JA, Aro A, Hu H, Ryan PB. Measurement variability associated with KXRF bone lead measurement in young adults. Environ Health Perspect. 2000;108(3):239-42. Available from. https://doi.org/10.1289/ehp.00108239.

34. Todd AC Calculating bone-lead measurement variance. Environ Health Perspect. 2000;108(5):383-6. https://doi.org/10.1289/ehp.00108383. 
35. McNeill FE, Stokes L, Chettle DR, Kaye WE. Factors affecting in vivo

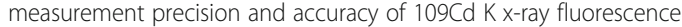
measurements. Phys Med Biol. 1999;44(9): 2263-73. https://doi.org/10.1088/ 0031-9155/44/9/313

36. Arora M, Weuve J, Weisskopf MG, Sparrow D, Nie H, Garcia Rl, et al. Cumulative lead exposure and tooth loss in men: the normative aging study. Environ Health Perspect. 2009;117(10):1531-4.

37. Behinaein S, Chettle DR, Marro L, Malowany M, Fisher M, Fleming DEB, et al. Factors influencing uncertainties of in vivo bone lead measurement using a ${ }^{109} \mathrm{Cd}$ K X-ray fluorescence clover leaf geometry detector system. Environ Sci Process Impacts. 2014;16(2):2742-51. https://doi.org/10.1039/ c4em00446a.

38. Todd AC, Chettle DR. In vivo X-ray fluorescence of lead in bone: review and current issues. Environ Health Perspect. 1994;102(2):172-7. https://doi.org/10. 1289/ehp.94102172.

39. Naicker $\mathrm{N}$, de Jager $\mathrm{P}$, Naidoo $\mathrm{S}$, Mathee A. Is there a relationship between lead exposure and aggressive behavior in shooters? Int J Environ Res Public Health. 2018.15(7). https://doi.org/10.3390/ijerph15071427.

40. Getso KI, Hadejia IS, Sabitu K, Nguku PM, Poggensee G, Aliyu HM, et al. Prevalence and determinants of childhood Lead poisoning in Zamfara state, Nigeria. J Heal Pollut. 2014;4(6):1-9. Available from. https://doi.org/ 10.5696/2156-9614-4-6.1.

41. Chuang HY, Chao KY, Tsai SY. Reversible neurobehavioral performance with reductions in blood lead levels-a prospective study on lead workers. Neurotoxicol Teratol. 2005;27(3):497-504.

\section{Publisher's Note}

Springer Nature remains neutral with regard to jurisdictional claims in published maps and institutional affiliations.

Ready to submit your research? Choose BMC and benefit from:

- fast, convenient online submission

- thorough peer review by experienced researchers in your field

- rapid publication on acceptance

- support for research data, including large and complex data types

- gold Open Access which fosters wider collaboration and increased citations

- maximum visibility for your research: over $100 \mathrm{M}$ website views per year

At $\mathrm{BMC}$, research is always in progress.

Learn more biomedcentral.com/submissions 